\title{
Identifying differences in the regionalisation of low flows and low flow salinity
}

\author{
$\underline{\text { N.M. Malana }}{ }^{\text {a }}$, J. Costelloe a , H.M. Malano a ${ }^{\text {, and A.W. Western }}{ }^{\text {a }}$ \\ ${ }^{a}$ Department of Infrastructure Engineering, The University of Melbourne, Victoria 3010 Australia. \\ Email: m.malana@pgrad.unimelb.edu.au
}

\begin{abstract}
Water resources in many parts of the world are experiencing degradation of the resource base and stress due to increasing demands. River diversions, clearing of native vegetation and irrigated agriculture can lead to salinisation of water and land resources and result in significant economic losses. The salinisation problem is a major threat to environmental sustainability. In order to better manage and control further degradation of limited water resources, predictions of water resource quantity as well as quality have to be improved.
\end{abstract}

This study is motivated by salinisation of streams in response to landuse changes and aims to examine links between the regional behaviour of low flows and stream salinity. Stream salinity can be used as a hydrological response to catchment scale anthropogenic changes and a measure of stream water quality. It is observed that low flows have usually higher salt concentrations compared to high and medium streamflows. However, the question is how low flow salinity is associated with low flows, as the observed data on low flows and low flow salinity show great variability in space and time. This paper analyses the relationship between low flows and low flow salinity. In order to explain the spatial variability in low flows and low flow salinity in a sub-humid region, this study develops regional regression models, and identifies differences in the two regional models.

We analysed the variability in low flows and low flow salinity with the help of catchment-scale observed data on climate, vegetation, geology, soils, catchment physical attributes, groundwater, streamflow and salinity from 78 catchments across Victoria, Australia. Physical characteristics of the study catchments were derived with the help of a digital elevation model of the area. Data on spatial variability in land use, vegetation and geology and time series of streamflow and salinity and groundwater salinity were used in the analysis.

Statistical methods, including correlation, stepwise regression and multiple regression, were used to regionalize low flows and low flow salinity for the study catchments. Data analysis of the study catchments shows that there is a strong correlation between low flows and low flow salinity in a log-log space. However, it is difficult to predict low flow salinity on the basis of low flow data alone. Although low flows and low flow salinity are correlated, their spatial variability in the regional models is represented by different variables. Sustained low flows are associated with increase in moisture supply (P/Eo), catchment efficiency to convert rainfall to runoff $(\mathrm{R} / \mathrm{P})$ and negatively correlated with evapotranspiration ratio (E/P). Low flow salinity, on the other hand, is positively associated with evapotranspiration ratio $(\mathrm{E} / \mathrm{P})$ and catchment flatness and negatively correlated with evapotranspiration efficiency (E/Eo).

Key words: Regionalisation, low flows, low flow salinity 


\section{INTRODUCTION}

The biophysical impacts of landuse change that modify catchment water and salt balance are variable and depend on factors such as rainfall, climate, hydrogeology and topography (Gilfedder et al. 2009). Changes in water balance due to landuse may lead to mobilization of salt and its build up near the soil surface and in water flow paths (van Dijk et al. 2008). van Dijk et al. (2008) demonstrated a strong relationship between groundwater salinity and low flow salinity. A common source of low flows is groundwater discharge (Smakhtin 2001) and so salt concentration in low flows may represent groundwater salinity. The observed data on low flow salinity show great variability in space and time. A number of previous regional studies have estimated the characteristics of low flows (e.g. Yu et al. 2002, Nathan and McMahon 1992, Vogel and Kroll 1992); however, we focus on the regional analysis of low flow salinity.

Reduced evapotranspiration as a result of forest clearing and replacement with short rooted crops causes increase in groundwater recharge and rise in groundwater table and salt build up in the root zone (Zhang et al. 1999). Forest clearing can also increase streamflows and provide additional flows for dilution of saline inflows into stream (ibid). However, the dilution of salt inflows into a stream depends on the rainfall zone (ibid). In the medium rainfall zones, forest clearing may result in small increase in streamflow but the increase in salt concentration can be significantly higher (Zhang et al. 1999). Walker et al. (2007) highlighted the importance of time scales in groundwater response to landuse change. The response time may range from few years for a fast responding groundwater flow system (local scale) to hundreds of years for slow responding system (regional scale).

Relating the physical characteristics of a catchment to its hydrological response is regarded as a fundamental problem in hydrology (Post and Jakeman 1996), particularly for predicting the possible effect of catchment change on its hydrological response. Berger and Entekhabi (2001) demonstrated that the variability of different basins can be explained with the help of topographic indices such as median surface slope, relief ratio, drainage density and long term climate, soil and hydrologic responses. They pointed out the importance of climate as expressed by annual wetness ratio (annual precipitation (P)/annual potential evapotranspiration (Eo)) for hydrological processes and as an indicator of atmospheric supply and demand of moisture, with a high value indicating a moist environment.

Spatial variability in stream salinity is a function of climate, topography and vegetation (van Dijk et al. 2008). For example, Davey et al. (2006) reported that flatter areas ( $<2$ degrees slope) overlain by saline soils and falling in $500-850 \mathrm{~mm} /$ year rainfall zone are vulnerable to salinisation. They explained that in drier areas (rainfall $<500 \mathrm{~mm} /$ year), water is not available in sufficient quantity to mobilize salts while in wetter areas (rainfall $>850 \mathrm{~mm} /$ year) salts are leached out of soils by rain water.

Temporal variability in low flows can be analysed with the help of streamflow time series while the spatial variability is explained by applying a regional analysis (Smakhtin 2001). Low flows are affected by climate, topography, geology, soils, groundwater, recharge, evapotranspiration, vegetation, and anthropogenic factors (ibid). In their regional analysis of low flows, Vogel and Kroll (1992) and Yu et al. (2002) identified drainage area, average basin slope and baseflow recession constant as the key variables explaining variability of low flow statistics.

This paper has three main objectives as follows: first, to investigate the extent of correlation between the low flows and low flow salinity for the study catchments; second, to identify the key factors that can explain spatial variability in low flows and low flow variability; and third, to identify the main differences in the regionalisation of low flows and low flow salinity in a sub-humid environment.

\section{METHODS}

The detail of data and sources of data used in the analysis is given in Table 1. The observed data on streamflow and salinity, climate, vegetation, geology, soils, catchment physical characteristics, and groundwater salinity were analysed from 78 catchments across Victoria, Australia. These catchments are from 17 river basins draining on either side of the Great Dividing Range. Time series of streamflows were analysed for variability in flow quantiles, flow duration curves and baseflow index. Baseflow index was estimated by using the Chapman and Maxwell method (Grayson et al. 1996). Stream salinity data consisted of mostly monthly observed values of stream salinity. The available stream salinity observations were analysed for deriving $10^{\text {th }}, 50^{\text {th }}$ and $90^{\text {th }}$ percentiles of stream salinity. Time series of streamflow and salinity covered different time periods and durations for different study catchments. The observed streamflow data was not available for about $1 / 6^{\text {th }}$ of study catchments. These were infilled by computed (modelled) streamflow for these catchments (Table 1). 
The study catchments were delineated with the help of a 90m resolution digital elevation model (DEM) (Jarvis et al. 2008). The size of catchments varies from $32 \mathrm{~km}^{2}$ to $6240 \mathrm{~km}^{2}$. There are no large dams in the study catchments. Terrain attributes were derived from the DEM, such as elevation, relief, aspect, length of streams, drainage index, slope index, area fractions with different slopes (up to $2 \%, 2 \%-4 \%$ and $4 \%-7 \%$ ), stream order (Strahler), and stream bifurcation ratio. The catchment scale variability in the climate (mean annual rainfall, actual evapotranspiration, and potential evapotranspiration), soils, geology and land-use attributes were analysed with the help of digital maps. Groundwater salinity was analysed from the timeseries of 10,000 bores in the region. An interpolated surface of mean salinity values of these groundwater bores was generated in ArcGIS by using the inverse distance method. The change in the native forest cover was estimated from the native vegetation maps of pre-European settlement (1788) and post-European settlement (1988). Statistical techniques such as the correlation analysis, rank and percentiles, stepwise and multiple regression were used for the analysis.

Table 1. Data sources

\begin{tabular}{|c|c|}
\hline Data set & Source \\
\hline $\begin{array}{l}\text { Average annual } \\
\text { evapotranspiration }\end{array}$ & Bureau of Meteorology, Australia \\
\hline $\begin{array}{l}\text { Average annual potential } \\
\text { evapotranspiration }\end{array}$ & Bureau of Meteorology, Australia \\
\hline Digital elevation model (90m) & $\begin{array}{l}\text { Jarvis A., Reuter, H.I., Nelson, A., and Guevara, E. (2008). Hole-filled seamless SRTM data V4, } \\
\text { International Centre for Tropical Agriculture (CIAT), <http://srtm.csi.cgiar.org.> }\end{array}$ \\
\hline Geology & $\begin{array}{l}\text { Raymond, O.L., Liu, S.F., Kilgour, P., Retter, A.J., Connolly, D.P. (2007). Surface Geology of } \\
\text { Australia 1:1,000,000 scale, Victoria - 3rd edition [Digital Dataset], Canberra: Geoscience Australia. } \\
<\text { http://www.ga.gov.au> }\end{array}$ \\
\hline Groundwater salinity & $\begin{array}{l}\text { Peterson, T. and Wealands, S. (2011). Groundwater Database (Version 1.11), Civil and } \\
\text { Environmental Engineering Department, The University of Melbourne, Victoria, Australia }\end{array}$ \\
\hline $\begin{array}{l}\text { Time series of observed and } \\
\text { computed streamflow and } \\
\text { salinity }\end{array}$ & $\begin{array}{l}\text { Department of Sustainability and Environment, Victoria, Australia. } \\
<\text { http://www.vicwaterdata.net/vicwaterdata }>\end{array}$ \\
\hline
\end{tabular}

\section{RESULTS}

\subsection{Correlation between low flows and low flow salinity}

The $90^{\text {th }}$ percentiles streamflows (Q90, i.e. the streamflow exceeded or equalled 90 percent of the observed data period), were used as a low flow measure. However, there are 23 ephemeral catchments in our study area that have zero flows for the $90^{\text {th }}$ percentile. In order to cope with this problem, zero flow days were removed from the observed streamflows of all the study catchments. The $90^{\text {th }}$ percentiles of non-exceedance salinity (C90, i.e. salt concentration in streamflow not exceeded 90 percent of observed data period), were used as a measure of low flow salinity. Both the low flows (Q90) and low flow salinity (C90) were derived from the observed

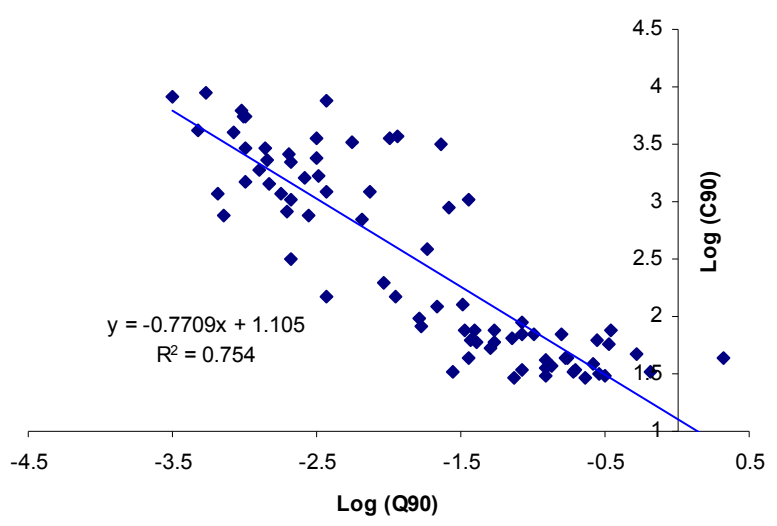

Figure 1. Correlation between Q90 and C90. data. It is assumed that low flow salinity (C90) is associated with the low flows (Q90).

The observed data for low flows $(\mathrm{mm} / \mathrm{d})$ and low flow salinity $(\mathrm{mg} / \mathrm{l})$ were log-transformed and plotted on a scatter chart. Figure 1 shows the correlation between Q90 and C90 for the 78 study catchments. This 
relationship was further tested for the 23 ephemeral catchments (Figure 2). The correlation between low flows and low flow salinity improves for the ephemeral catchments.

In order to estimate low flow salinity (C90) based on low flows (Q90), the relationship between low flows and low flow salinity was calibrated on 58 catchments and validated on the remaining 20 study catchments. A comparison of observed and modelled C90 values is shown in Figure 3. This analysis demonstrates that the relationship between low flows and low flow salinity is poor and low flow salinity depends on factors other than low flows (see Section 3.3).

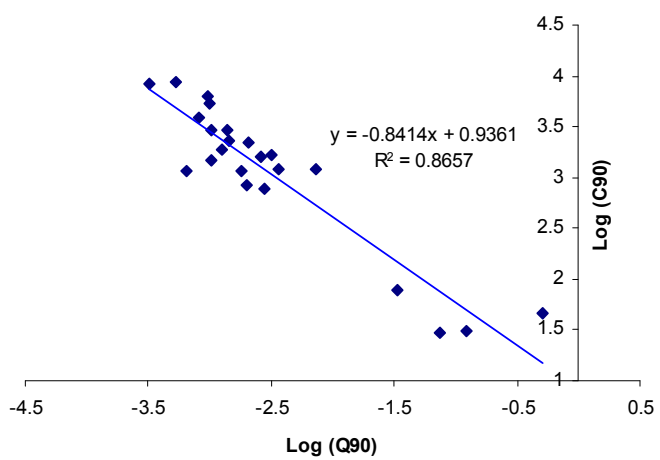

Figure 2. Correlation between Q90 and C90 for ephemeral catchments.

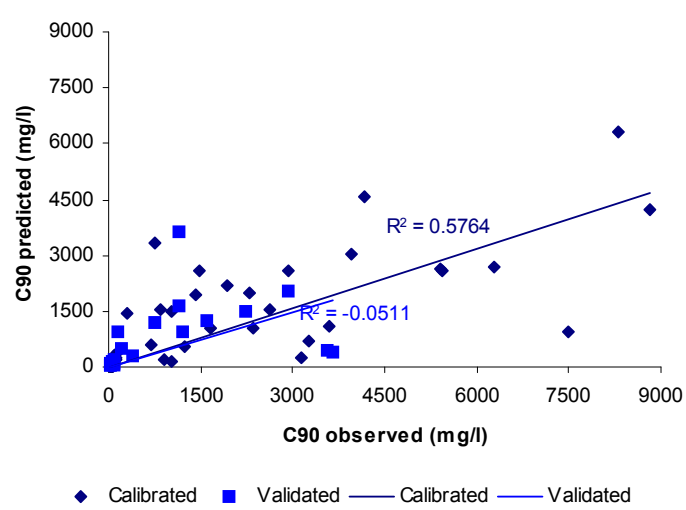

Figure 3. Comparison of observed and predicted C90.

\subsection{Spatial variability in low flows}

Low flows show a significant positive correlation with mean annual streamflow $(\mathrm{MAF})$, runoff ratio $(\mathrm{R} / \mathrm{P})$, wetness ratio $(\mathrm{P} / \mathrm{Eo})$, slope index SI (relief divided by square root of catchment area), mean annual rainfall (mAR) and negative correlation with evapotranspiration ratio (E/P) (see Table 2). All variables having correlation coefficients with Q90 greater than 0.40 are shown in Table 2.

Stepwise regression was used to identify variables explaining variability in lows flows (Q90). The analysis found annual runoff ratio $(\mathrm{R} / \mathrm{P})$, wetness ratio $(\mathrm{P} / \mathrm{Eo})$, and evapotranspiration ratio $(\mathrm{E} / \mathrm{P})$ as the key variables for low flows. Based on these three variables, a regional model $\left(\mathrm{R}^{2}=0.90\right)$ was developed for all 78 study catchments using multiple regression. The model is given in equation (1) as follows:

$$
Q 90=0.117\left(\frac{P}{E O}\right)+0.234\left(\frac{R}{P}\right)-0.12\left(\frac{E}{P}\right)
$$

The 78 study catchments were divided into two groups for assessing the effectiveness of the regional model, 58 catchments for model calibration and 20 catchments for validation. The regional model calibrated on 58 catchments $\left(\mathrm{R}^{2}=0.91\right)$, is given in equation (2) as follows:
Table 2. Correlation of variables with low flows (Q90)

\begin{tabular}{lrrrrrrr}
\hline Variable & Q90 & P/Eo & \multicolumn{1}{c}{ R/P } & E/P & SI & mAR & $\mathrm{mAF}$ \\
\hline Q90 & 1.00 & & & & & & \\
P/Eo & 0.51 & 1.00 & & & & & \\
R/P & 0.91 & 0.30 & 1.00 & & & & \\
E/P & -0.44 & -0.97 & -0.25 & 1.00 & & & \\
SI & 0.51 & 0.67 & 0.37 & -0.67 & 1.00 & & \\
mAR & 0.48 & 1.00 & 0.28 & -0.97 & 0.67 & 1.00 & \\
mAF & 0.92 & 0.32 & 1.00 & -0.25 & 0.38 & 0.29 & 1.00 \\
\hline
\end{tabular}

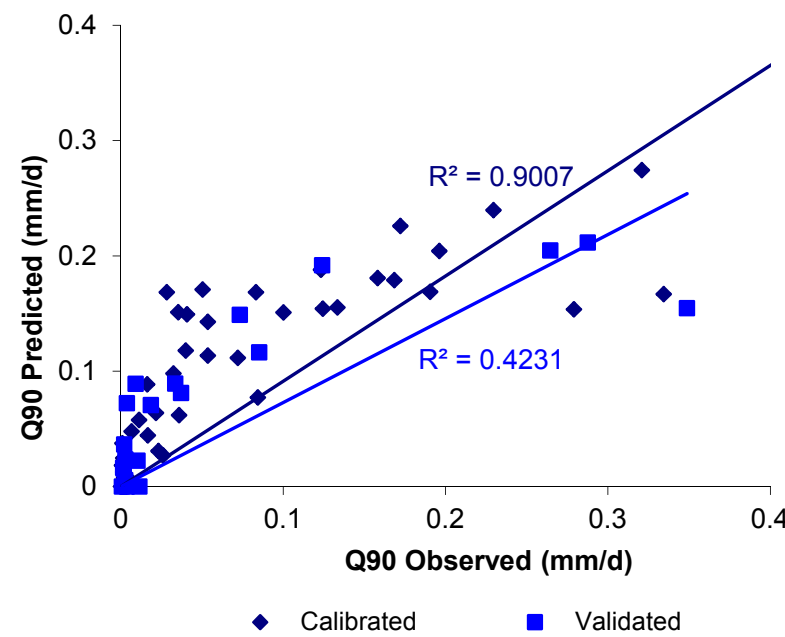

Figure 4. Comparison of observed and predicted low flows (Q90). 


$$
Q 90=0.116\left(\frac{P}{E O}\right)+0.233\left(\frac{R}{P}\right)-0.115\left(\frac{E}{P}\right)
$$

A comparison of observed and predicted low flows (Q90) is shown in Figure 4 for both the calibration and validation datasets. The model predicted negative values for observed low flows less than $0.004 \mathrm{~mm}$. As negative low flows are not practical, the model was constrained to a minimum of zero.

\subsection{Spatial variability in low flow salinity}

Physical catchment characteristics, climatic variables and landuse measures are closely associated with low flow salinity (C90). Table 3 shows variables significantly correlated (coefficients $>0.50$ ) with the low flow salinity (C90).

Table 3. Correlation of variables with stream salinity $\left(\mathrm{C}_{90}\right)$

\begin{tabular}{lrrrrrrrrrrr}
\hline Variable & \multicolumn{1}{c}{ C90 } & \multicolumn{1}{c}{ E/P } & Eo/P & E/Eo & P/Eo & mElev & SL1 & SL2 & mSL & nVeg & DLP \\
\hline C90 & 1.00 & & & & & & & & & & \\
E/P & 0.70 & 1.00 & & & & & & & & & \\
Eo/P & 0.70 & 0.98 & 1.00 & & & & & & & & \\
E/Eo & -0.55 & -0.74 & -0.86 & 1.00 & & & & & & & \\
P/Eo & -0.63 & -0.97 & -0.96 & 0.80 & 1.00 & & & & & & \\
mElev & -0.57 & -0.84 & -0.84 & 0.74 & 0.88 & 1.00 & & & & & \\
SL1 & 0.63 & 0.75 & 0.76 & -0.61 & -0.71 & -0.71 & 1.00 & & & & \\
SL2 & 0.68 & 0.90 & 0.89 & -0.71 & -0.87 & -0.82 & 0.81 & 1.00 & & & \\
mSL & -0.57 & -0.85 & -0.83 & 0.66 & 0.86 & 0.82 & -0.73 & -0.89 & 1.00 & & \\
nVeg & -0.62 & -0.79 & -0.78 & 0.64 & 0.77 & 0.70 & -0.73 & -0.81 & 0.74 & 1.00 & \\
DLP & 0.56 & 0.72 & 0.64 & -0.43 & -0.72 & -0.65 & 0.52 & 0.73 & -0.74 & -0.84 & 1.00 \\
\hline Where & E/Ptand & & & & & & & & & & \\
\end{tabular}

Where $E / P$ stands for mean annual evapotranspiration ratio, $E_{o} / P$ index of dryness, and $E / E_{o}$ evapotranspiration efficiency, $\mathrm{P} / \mathrm{Eo}$ wetness ratio, $\mathrm{mElev}$ catchment mean elevation, $S L 1$ catchment fraction having up to $2 \%$ slope, $S L 2$ catchment fraction having slope $2 \%-4 \%$, mSL mean slope, $n V e g$ catchment fraction having native forests, and $D L P$ stands for catchment fraction under dryland pasture.

By using stepwise regression method, annual evapotranspiration ratio (E/P), evapotranspiration efficiency (E/Eo) and catchment fraction having slope up to $2 \%$ (SL1) were found to be the key variables explaining the spatial variability of low flow salinity (C90) in the study region. Based on these three variables, a regional multiple regression model for all 78 study catchments was developed $\left(\mathrm{R}^{2}=0.66\right)$, given is equation (3) as follows:

$C 90=4698.7\left(\frac{E}{P}\right)-3733.8\left(\frac{E}{E o}\right)+29.06 S L 1$

Following the calibration and validation procedure for low flows (explained in Section 3.2), equation (4) represents the multiple regression regional model for the 58 calibration catchments $\left(\mathrm{R}^{2}=0.67\right)$, given as follows:

$$
C 90=5308\left(\frac{E}{P}\right)-4169\left(\frac{E}{E o}\right)+27.54 S L 1
$$

The model given in equation (4) was applied to the validation dataset of 20 catchments. The model predicted negative values for the observed C 90 values less than $80 \mathrm{mg} / 1$, and therefore, it was constrained to a minimum of zero. Figure 5 shows a comparison of observed and predicted low flow salinity for both the calibrated and validated datasets. 


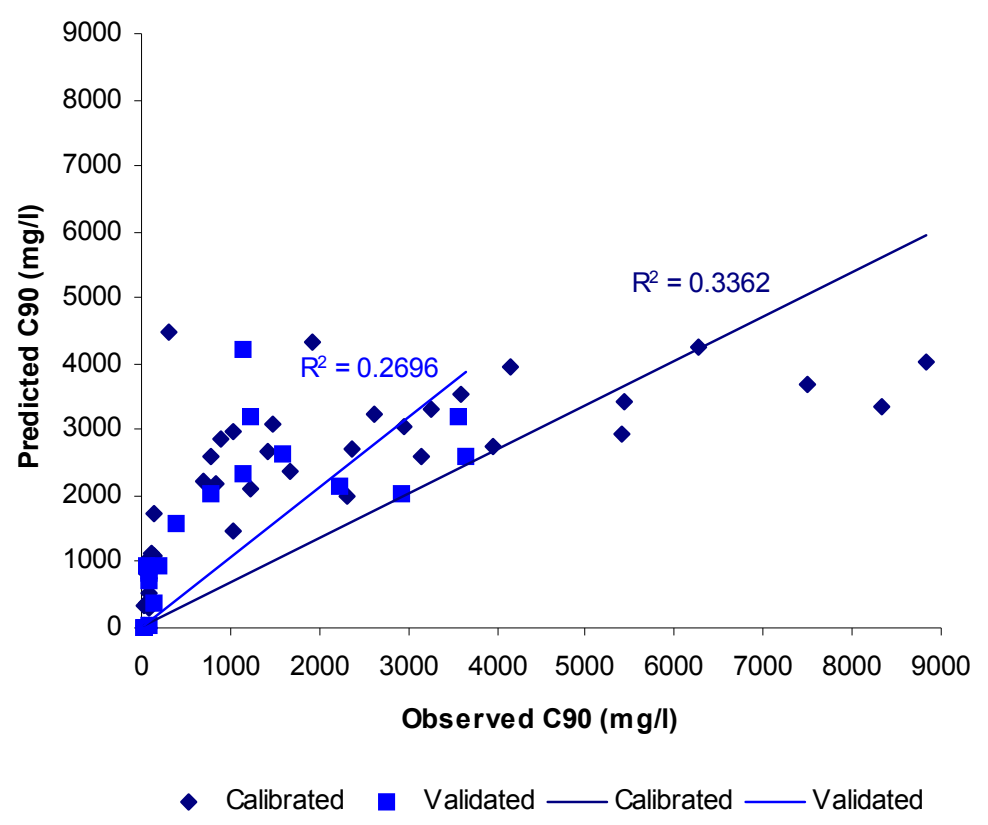

Figure 5. Comparison of observed and predicted low flow salinity (C90).

\section{DISCUSSION AND CONCLUSION}

In a log-log space, a strong correlation between low flows and low flow salinity is observed based on the observed data (see Figure 1 and 2). This correlation improves in the case of ephemeral catchments (Figure 2). Out of 23 ephemeral catchments in our study, 18 fall in the medium rainfall zone $(500-850 \mathrm{~mm} /$ year). Low flow salinity (C90) was higher for those catchments that underwent considerable forest clearing. This analysis endorses the earlier studies (e.g. Zhang et al. 1999) that forest clearing in the medium rainfall zone catchments can increase salt concentrations in streamflow. However, predicting low flow salinity on the basis of low flows alone gives poor results (Figure 3). It is worth noting that the low flow salinity values (C90) derived from the observed data (Section 3.1) corresponded well with the C90 values obtained from the paired C90-Q90 data.

The regional analysis of low flows demonstrated that spatial variability in low flows can be explained with the help annual runoff ratio $(\mathrm{R} / \mathrm{P})$, wetness ratio $(\mathrm{P} / \mathrm{Eo})$, and evapotranspiration ratio $(\mathrm{E} / \mathrm{P})$. Low flows are positively correlated with mean annual runoff ratio $(\mathrm{R} / \mathrm{P})$ and wetness ratio $(\mathrm{P} / \mathrm{Eo})$ that range from 0.02 to 0.50 and 0.49 to 1.75 for our study catchments. Higher values of annual wetness ratio indicate more supply of atmospheric moisture (Berger and Entekhabi 2001) and are expected to result in sustained low flows. Higher annual runoff ratio represents the capacity of a catchment to covert rainfall into streamflow. Low flows are negatively correlated with the mean annual evapotranspiration ratio (E/P) that range from 0.36 to 0.98 for the study catchments. A higher value of evapotranspiration ratio corresponds to the lack of moisture supply and increase in dryness (see Table 3 and 2). Regional analysis of low flows shows that long term annual climate indices can be used for the prediction of low flows.

The regional model of low flow salinity demonstrates that climate and catchment flatness influence spatial variability in low flow salinity. Mean annual evapotranspiration ratio $(\mathrm{E} / \mathrm{P})$ and evapotranspiration efficiency (E/Eo) represent $63 \%$ variance of the low flow salinity in the study region. The addition of catchment flatness (SL1) only slightly increases model efficiency. Low flow salinity is significantly positively correlated with evapotranspiration ratio (E/P) and negatively correlated with evapotranspiration efficiency (E/Eo) that range from 0.46 to 0.68 for the study catchments. Thus catchments with less annual rainfall and less native forest cover are vulnerable to increase in low flow salinity. The inclusion of additional variables representing catchment physical attributes and landuse data did not increase the model efficiency considerably. However, stream salinity is also influenced by catchment physical characteristics in addition to climate (van Dijk et al. 2008); this explains the low performance of the regional model for low flow salinity (equation 3 and 4 ). 
Malana et al. (submitted for MODSIM 2011) show that regional model of low flow salinity can be improved by analysing the changes in vegetation cover with the help of an annual evapotranspiration model.

Although low flows and low flow salinity are correlated (Figure 1 and 2), their spatial variability in the regional models is represented by different variables. Sustained low flows are associated with increase in moisture supply $(\mathrm{P} / \mathrm{Eo})$ and catchment efficiency to convert rainfall to runoff $(\mathrm{R} / \mathrm{P})$ and negatively correlated with evapotranspiration ratio $(\mathrm{E} / \mathrm{P})$. Low flow salinity, on the other hand, is positively associated with evapotranspiration ratio $(\mathrm{E} / \mathrm{P})$ and catchment flatness and negatively correlated with evapotranspiration efficiency (E/Eo). As already indicated, increase in evapotranspiration ratio indicates increase in catchment dryness. Whereas, increase in evapotranspiration efficiency $(\mathrm{E} / \mathrm{Eo})$ corresponds to increase in moisture availability and native forest cover. As a number of variables provide similar information about the catchment, the explanatory variables identified for the regional models are not necessarily the ones having high correlation with Q90 or C90. The underlying relationships for the regional regression models appear to be non-linear, as the models tend to over predict low values of Q90 and C90 and under-predict high values.

This paper investigated differences in the regional models of low flows and low flow salinity by finding key variables expected to influence their spatial variability. The 78 study catchments represent 17 diverse river basins in Victoria, Australia, with low flows (Q90) ranging from $0.0003 \mathrm{~mm} / \mathrm{d}$ to $2.1 \mathrm{~mm} / \mathrm{d}$ and low flow salinity (C90) covering a range from $29 \mathrm{mg} / 1$ to $8832 \mathrm{mg} / \mathrm{l}$. Given the heterogeneity of the study catchments and the use of long term and limited catchment-scale information used in the analysis, the results of the study are encouraging. Further improvement in the regional model of low flows can be achieved by dividing the study region into groups of homogeneous catchments with respect to key variables identified. For regional model of low flow salinity, in addition to forming groups of homogeneous catchments, performance of regional model can be improved by addition of variables that can better explain physical characteristics of catchment. The use of non-linear relationships or data transformation is likely to improve prediction of the regional models for Q90 and C90.

\section{REFERENCES}

Berger, K.P., and Entekhabi, D. (2001). Basin hydrologic response relations to distributed physiographic descriptors and climate. Journal of Hydrology, 247, 169-182.

Davey, S.M., Baker, P., Frakes, I., and Mullen I. (2006). Opportunities for commercial forestry in Australia. Bureau of Rural Sciences, Australian Government.

Gilfedder, M., Walker, G.R., Dawes, W.R., and Stenson, M.P. (2009). Prioritisation approach for estimating the biophysical impacts of land-use change on stream flow and salt export at a catchment scale. Environmental Modelling \& Software, 24, 262-269.

Grayson, R. B., Argent, R. M., Nathan, R. J., McMahon, T. A., and Mein, R. G. (1996). Hydrological recipes: estimation techniques in Australian hydrology. Cooperative Research Centre for Catchment Hydrology, Victoria, Australia. 125pp.

Jarvis A., Reuter, H.I., Nelson, A., and Guevara, E. (2008). Hole-filled seamless SRTM data V4. International Centre for Tropical Agriculture (CIAT), <http://srtm.csi.cgiar.org.>.

Malana, N.M., Costelloe, J., and Malano, H.M. (submitted for MODSIM 2011). A top-down approach to understand the effect of vegetation changes on stream salinity.

Nathan, R.J. and McMahon, T.A. (1992). Estimating low flow characteristics in ungauged catchment. Water Resources Management, 6, 85-100.

Post, D. A. and Jakeman, A. J. (1996). Relationships between catchment attributes and hydrological response characteristics in small Australian mountain ash catchments. Hydrological Processes, 10, 877-892.

Smakhtin, V.U. (2001). Low flow hydrology: a review. Journal of Hydrology, 240, 147-186.

van Dijk, A.I.J.M., Gilfedder, M. and Austin, J. (2008). Influence of climate, terrain and land cover on stream salinity in southeastern Australia, and implications for management through reforestation. Hydrological Processes, 22, 3275-3284.

Vogel, R.M. and Kroll, C.N. (1992). Regional geohydrologic-geomorphic relationships for the estimation of low-flow statistics. Water Resources Research, 28(9), 2451-2458.

Walker, G., Zhang, L., Dawes, W., Gilfedder, M., Brown, A., Hickel, K., and Evans, R. (2007). Flow and salinity impacts of afforestation in upland dryland catchments: Perspective from the "catchment characterisation" project 2000-2004. CSIRO Land and Water Science Report 13/07.

Yu, P-S., Yang, T-C., and Liu, C-W. (2002). A regional model of low flow for southern Taiwan. Hydrological Processes, 16, 2017-2034.

Zhang, L., Dawes, W.R., and Walker, G.R. (1999). Predicting the effect of vegetation changes on catchment average balance. Technical report 99/12, Cooperative Research Centre for Catchment Hydrology, CSIRO Land and Water. 